\title{
La importancia de la comunicación y liderazgo: herramientas para métodos efectivos de formación y organización educativa.
}

The importance of communication and leadership: tools for effective methods of training and educational organization.

A importância da comunicação e da liderança: ferramentas para métodos eficazes de formação e organização educacional.

\section{ARTÍCULO ORIGINAL}

\section{Celestino Reyes Jiménez}

celestino.reyesjmz@gmail.com

https://orcid.org/0000-0002-9819-5904

Recibido 28 de Setiembre 2021 | Arbitrado y aceptado 28 de Setiembre 2021 | Publicado en 01 Octubre 2021

\section{RESUMEN}

La intención de este artículo, es explicar los conceptos de comunicación y liderazgo como pilares del método formativo para las organizaciones educativas. La importancia de la comunicación asertiva es un reto constante para que los equipos y grupos sean capaces de una interacción continua y efectiva, siendo parte también de los pilares que conforman al liderazgo. Estos juegan un papel crucial en la gestión como un rol fundamental para alcanzar altos estándares de calidad en el servicio y con ello una mejor formación del ser humano como un individuo pleno consigo mismo y con su entorno hacia el bien común.

El objetivo es mostrar de una manera clara la correlación de estas 2 herramientas y su impacto en la mejora educativa al ser variables que inciden en el desempeño de este sistema, al ser esenciales para que los directivos diseñen y desarrollen técnicas de mejora continua y de una cultura de innovación y aprendizaje.

Una educación, por y para el liderazgo, utilizando como base la comunicación efectiva y concisa, constituye un factor determinante para el perfeccionamiento de la calidad educativa que incide en la sociedad y que busca ante todo el desarrollo integral de los individuos.

Palabras clave: comunicación, liderazgo, organización, conductas, motivación.

\section{ABSTRACT}

The intention of this article is to explain the concepts of communication and leadership as pillars of the training method for educational organizations. The importance of assertive communication is a constant challenge for teams and groups to be capable of continuous and effective interaction, also being part of the pillars that make up leadership. These play a crucial role in management as a fundamental role to achieve high standards of quality in service and with it a better training of the human being as an individual full with himself and with his environment towards the common good.

The objective is to clearly show the correlation of these 2 tools and their impact on educational improvement as they are variables that affect the performance of this system, as they are essential for managers to design and develop techniques for continuous improvement and a culture of innovation and learning.

An education, by and for leadership, using effective and concise communication as a basis, constitutes a determining factor for the improvement of educational quality that affects society and that seeks above all the integral development of individuals.

Keywords: communication, leadership, organization, behaviors, motivation.

\section{RESUMO}

A intenção deste artigo é explicar os conceitos de comunicação e liderança como pilares do método de formação para organizações educacionais. A importância da comunicação assertiva é um desafio constante para que equipes e grupos sejam capazes de uma interação contínua e efetiva, também fazendo parte dos pilares que compõem a liderança. Estes desempenham um papel crucial na gestão, sendo fundamental para o alcance de elevados padrões de qualidade no serviço prestado e com isso uma melhor formação do ser humano como pessoa plena consigo mesmo e com o seu meio para o bem comum.

O objetivo é mostrar com clareza a correlação destas 2 ferramentas e o seu impacto na melhoria educacional, visto que são variáveis que afetam o desempenho deste sistema, pois são essenciais para que os gestores desenhem $\mathrm{e}$ desenvolvam técnicas de melhoria contínua e uma cultura de inovação e aprendizagem .

Uma educação, por e para lideranças, tendo como base uma comunicação eficaz e concisa, constitui um fator determinante para a melhoria da qualidade educacional que afeta a sociedade e que visa acima de tudo o desenvolvimento integral das pessoas.

Palavras-chave: comunicação, liderança, organização, comportamentos, motivação. 


\section{INTRODUCCIÓN}

Desde el origen de los tiempos, los humanos hemos ido evolucionando de la mano de la innovación y cambios, adaptándose a nuevas reglas con el constante miedo de perder el control ante los problemas que se presenten durante la curva de aprendizaje y dominio de estas nuevas prácticas. El mayor problema surge cuando las propuestas conceptuales de convierten en modismos por los riesgos de la aplicación del concepto según la conveniencia y preferencia de cada individuo, más allá de su utilidad social o científica, donde es importante diferenciar de una moda o tendencia la necesidad real del uso de la comunicación y liderazgo en lo educativo, como un facilitador (e irónicamente al mismo tiempo) obligado para la relación innata entre ambos.

El ámbito educativo en pleno siglo XXI se ve afectado por variables internas y externas que exigen un conjunto de cambios significativos, por la necesidad latente de responder con éxito a las demandas de la sociedad, por lo que todas las organizaciones educativas suman sus esfuerzos para mejorar y lograr una calidad tangible en la formación estudiantil, adaptando conceptos teóricos con una misma visión: la reestructuración funcional del tipo de liderazgo que los directores asumen al momento de dirigir las actividades que desempeñarán los docentes.

La comunicación asertiva se muestra además como un desafío claro para que los grupos y equipos puedan trabajar de una forma efectiva, ya que, de no ser así, pueden existir complicaciones dentro de las entidades educativas, usando el ejemplo previo de la reestructuración funcional, si el personal docente no estuviera de acuerdo con las propuestas de actividades a ejecutar. Es por ello que la comunicación es un pilar en todo el contexto educativo. El liderazgo entonces va de la mano para que exista un ecosistema de integridad, tolerancia y respeto, para apoyar a todos los que forman parte de la institución para orientar, acompañar y mejorar los procesos del centro educativo, todos actuando hacia una misma meta o fin.

Si bien no existe una fórmula mágica que nos permita tener una comunicación y liderazgo completamente efectivo en todo momento, es bien sabido que es un reto constante que amerita nuestra atención, al igual que la implementación de una implementación genuina ante los procesos educativos, cuestión que iremos comprendiendo detalladamente a lo largo de este artículo. 


\section{TEMAS Y SUBTEMAS.}

\section{LA COMUNICACIÓN.}

Podríamos encontrar muchas definiciones sobre que es la comunicación, pero todas coinciden en que, se trata de un proceso en el que se produce un cambio modificador para los involucrados en ella, y que tiene como elementos diferenciadores, un emisor, un receptor y un canal para transmitirla. Cuando existe la comunicación, los roles que la conforman pueden intercambiarse entre ellos mismos, lo que conocemos como retroalimentación, ya que la respuesta ante el primer planteamiento de un emisor, provoca un agente modificador en el nuevo emisor que anteriormente era el receptor.

Es entonces cuando la comunicación educativa es comprendida y se vuelve más fácil de explicar: es una variable que se produce en un contexto especifico en el ámbito educativo y es una condicionante de la educación en si misma: sin esta comunicación no puede existir educación y menos aún, un aprendizaje. He ahí la importancia de la adquisición de capacidades de comunicación acertadas, como competencia imprescindible de los docentes, ya que está ligada a la capacidad de los logros educativos de la sociedad estudiantil.

Berlo (1969) diseñó un modelo comunicativo que estable en el proceso de la comunicación educativa al docente y al discente, siendo también involucrados los contenidos y el soporte educativos, los medios didácticos y los procesos de codificación y decodificación para una retroalimentación. En este proceso, el docente al ser el emisor, realiza un proceso mental de codificación de contenido educativo, creando mensajes transmitibles por medio de un canal directo que desemboca en el discente, como primer receptor, que realiza su propio proceso mental de decodificación e interpretación, funcionando como un estímulo para generar un mensaje de respuesta que puede coincidir o discrepar entre los demás, y que permite que los roles de emisor del docente y receptor del discente se intercambien.

Este mecanismo se repite en reiteradas ocasiones con el único fin de realizar un intercambio reciproco de conocimientos, procedimientos y actitudes que constituyen la finalidad de la educación y enseñanza.

Según Mario Kaplún, (1997) existen dos modos de entender a la educación y el uso de los medios de comunicación en la enseñanza: el vertical y unidireccional, y el 
que considera al educando como sujeto de un proceso en el que se aprende dey con los otros. En el primer caso, el uso de los medios reproducirá la imposibilidad de una relación dialógica. En el segundo, ese uso se lo hará en un espacio cuyos protagonistas son verdaderos interlocutores. (p.4)

La comunicación por sí sola no podría ser efectiva sin tomar en cuenta a lo que podríamos llamar, fieles complementos, como asertividad, claridad, empatía y escucha activa. Por su parte, (Elizondo, 2000) dijo que asertividad es la habilidad de expresar tus pensamientos, sentimientos y percepciones, de elegir cómo reaccionar y de hablar por tus derechos cuando es apropiado. Esto con el fin de elevar tu autoestima y de ayudarte a desarrollar tu autoconfianza para expresar tu acuerdo o desacuerdo cuando crees que es importante, e, incluso, pedir a otros un cambio en su comportamiento ofensivo. (p.17)

La claridad nos permite evitar expresiones poco entendibles o ambiguas y los tecnicismos. Esto va de la mano con una estructura adecuada del mensaje que quiere darse: ser simple y directo vale mucho más que dar vueltas y no ser concretos. La empatía para comprender y saber ponerme en el lugar del otro. Mas allá de ser un valor humano, es algo vinculado y requerido en cada actividad, en el ámbito educativo, es comprender a las personas dentro de los recintos estudiantiles y en las aulas, para acercarnos e identificar qué condiciones pueden significar barreras para que el aprendizaje y la enseñanza no se logren como es esperado. Por último, pero no menos importante, la escucha activa, ya que nunca hay que dar por sentado que lo que se comunica se comprendió en su totalidad, aunque el otro nos diga que sí. "Si a quien intentamos enseñar fracasa, somos responsables en parte de ese fracaso".

¿Que es necesario entonces para una comunicación educativa funcional?

Para lograr que este proceso sea eficaz y eficiente, debe tener algunos requisitos, que Murga Menoyo 1clasificó como funcionales.

Enlistó 6 directrices principalmente, que explicaré a continuación:

1) Persuasiva: Debe lograr su propósito en función a los objetivos y las metas. Todas las actitudes y procedimientos deben ser modificados en base a esto. 
2) Motivadora: Debe transmitir dentro la comunicación educativa estímulos que mantengan y capten el interés y atención del alumno, creándole una necesidad y una satisfacción dentro de ella, provocándole siempre la disponibilidad y predisposición a aprender.

3) Adaptiva: Este diferenciador es el que facilita la interacción del discente con el medio en el que interactuar mejorando las conductas que el sujeto lleva a cabo.

4) Estructurante: La comunicación debe ser capaz de promover, orientar y facilitar la construcción personal del discente, permitiendo identificar la estructura jerárquica del conocimiento que se transmite y su relación con los organizadores, teniendo coherencia externa e interna, con los componentes de la comunicación y con el resto de elementos que la conforman.

5) Facilitadora de inteligibilidad: Adaptar la información a las circunstancias que permiten su captación por parte del receptor, haciendo un análisis de los canales utilizados, el reforzamiento de mensajes, el ritmo y progresión de la comunicación.

6) Generalizadora: Debe tener la capacidad para provocar nuevas interconexiones y relaciones que den cabida a la aplicación de los conocimientos adquiridos a circunstancias reales del entorno.

Por otra parte, no se debe olvidar que es precisamente la comunicación en clase entre el profesor y el alumno uno de los elementos que más ayudan al primero a conocer la reacción del segundo ante lo que se expone, y a perfeccionar sus métodos basándose en la experiencia de los resultados observados. De ahí que la utilidad y rendimiento para el alumno dependa en gran medida de que el número de asistente se mantenga dentro de unos límites razonables, lo que además viene exigido por razones más directas de viabilidad, audición, comodidad, etc.

Los alumnos durante el aprendizaje, además de participar en los debates, lo que les exige una preparación previa, pueden discutir, consultar bibliografía y cuestionar la información recibida. Algunos autores opinan que el uso de los seminarios es preferible para cursos superiores, donde los alumnos pueden estar científicamente más preparados, 
sin embargo, la utilización de esta técnica no debe ser privativa de cursos elevados, puesto que es interesante la formación investigadora del alumno desde el principio, junto con otros objetivos como puede ser el desarrollo y mejora de la capacidad de su expresión oral.

\section{EL LIDERAZGO}

Ya que hemos comprendido a la comunicación, es tiempo de adentrarnos a lo que es el liderazgo.

Covey (1998), plantea el concepto de liderazgo centrado en principios, el cual tiene que ver con la transformación interna del ser humano, que lo llevará a influenciar a otros a largo plazo. Al complementar el término de liderazgo con lo educativo, adquiere un sentido formativo y de proyección en las instituciones escolares. Por tanto, el líder educativo se convierte en la persona que, con condiciones específicas frente al sentido de la educación, orienta a la comunidad educativa, como estudiantes, docentes, padres de familia y personas que manejan procesos educativos, en la búsqueda de mejorar la calidad educativa, el clima y la cultura organizacional en crecimiento personal, representada en la formación integral de las instituciones.

Un líder es la persona que guía e indica el camino que debe seguirse, que tiene cualidades aprendidas e inherentes, como sus conocimientos y habilidades, la forma en que se relaciona con los otros para apoyar y entender a los integrantes denotando su capacidad para tomar decisiones en tiempos de crisis. Podríamos definirlo como el individuo que ejerce mayor impacto en proporción a los otras en la dirección de una actividad en grupo.

Es entonces cuando el liderazgo puede ser catalogado como un fenómeno que se distribuye por toda la organización, que requiere se mire más allá de las funciones a las que el equipo directivo está destinado. En muchas ocasiones los docentes que no están involucrados en el liderazgo directamente comparten responsabilidades diferentes en las actividades y programas. Por ello, para comprender que tan complejo puede ser el tema, es importante tener un profundo conocimiento sobre las modalidades de distribución y el alcance que tiene. Mirar más allá de los directivos no es igual a no deber mirarlos también en ellos. En las actividades diarias educativas encontramos de forma frecuente indicios de la distribución del liderazgo, siendo imperante que en cierto grato todos en 
la comunidad educativa tengan cierto rango del mismo y sean capaces de adaptar modalidades de liderazgo compartido.

El liderazgo educativo promueve de forma sostenible el emprendimiento no solo de empresas, si no para promover el cambio de los mapas mentales de la comunidad estudiantil. Un líder educativo sabre transformar la realidad del entorno de manera innovadora y creativa, denotando siempre autonomía y desempeñando un papel de notable madurez personal e intelectual, liderando proyectos con visión, proactividad orientada a logros y al desarrollo con diferenciadores, para solucionar problemas desde la estrategia del pensamiento generando impacto en los ámbitos sociales. Posee como referente la ética, la responsabilidad y el comportamiento ejemplar: una actitud del sentido de humano con voluntad y con la suficiente madurez para tomar decisiones propias, que proyectan conciencia y son inteligentes.

Un aspecto fundamental en el liderazgo educativo es lograr el desarrollo de una plantilla de profesores idónea, con competencias que le permitan el ejercer con eficacia la tarea docente. Es entonces, trabajar en uno de los motivadores claves. Este concepto relacionado a lo educativo, denota la relación con la necesidad de transformación y cambio en el sistema, como se empodera del valor educativo, sus necesidad y contexto, permitiendo crear y mejorar los sistemas educativos actuales de la mano con la evolución tecnológica y los desafíos del desarrollo cultural.

Para poder entender más claramente, el Ministerio de Educación de Chile, por ejemplo, enlistó las siete practicas del liderazgo educativo:

1. Inspirar la necesidad de generar una transformación

2. Generar una visión orientada al futuro, creando organizaciones inteligentes con interés en una transformación gradual a nivel personal e institucional

3. Comunicar la visión, la acción, el compromiso y el aprendizaje.

4. Promover el trabajo en equipo

5. Brindar orientaciones y desarrollar el espíritu de logro alimentando las innovaciones 
6. Consolidar los avances en las transformaciones

7. Actualizar los aprendizajes, para que las organizaciones y sus elementos también aprendan de esta evolución.

En conclusión, un líder educativo es la persona que tiene la capacidad de influir en los estudiantes, docentes y administrativos, o bien, en general la comunidad educativa, para lograr objetivos que la institución delimite en su filosofía, para generar un valor diferenciador en sus procesos formativos. Pautt, (2011) plantea una posición interesante sobre la diferencia entre dirección y liderazgo. Portuondo (2004) cita a Bennis (1998) que explicaba que los directivos se centran en la gestión administrativa únicamente mientras que los lideres están enfocados en los cambios, denotando que el directivo administra, y un líder, innova.

Es claro que las organizaciones educativas requieren ambos enfoques, pero un directivo requiere imperativamente contar con cualidades de un líder para orientar exitosamente a la organización.

De igual forma Pautt (2011) asegura que la mera acción de dirigir, no se lidera, como en los procesos de control, los derechos y obligaciones que deben cumplirse, son acciones que mediante indicadores se pueden analizar y que por sí mismas, arrojan resultados.

Un líder educativo debe tener ciertas competencias, entre las que se encuentran:

1. Liderazgo centrado en principios: capacidad para desarrollar e implementar un espíritu de cumplimiento, compromiso y cooperación con su grupo, para orientar y guiar a los colaboradores hacia el logro de objetivos, siempre enfatizando el respeto y el sentido humano.

2. Emprendimiento: tener la capacidad de idear y poner en marcha soluciones nuevas y diferentes ante situaciones o complicaciones en el entorno.

3. Inteligencia emocional: capacidad de sentir, modificar, controlar y entender los estados de ánimo propios y ajenos. 
4. Orientación al cliente: para satisfacer, resolver y conocer a detalle con altos estándares de calidad las expectativas y necesidades presentes y futuras de los discentes y grupos de interés.

5. Orientación a resultados: para encaminar todas las acciones y esfuerzos al logro de metas y objetivos.

\section{¿QUÉ SON LOS MÉTODOS FORMATIVOS Y ORGANIZACIONALES?}

La dinámica de la sociedad actual ha roto paradigmas de la organización tradicional para permitir nuevos enfoques inteligentes y con mayor efectividad, manteniéndose en constante aprendizaje consigo mismas y con el entorno. Es por ello que ninguna organización, y mucho menos las educativas, pueden perder la viabilidad del contexto social, por lo que debe existir un liderazgo anteponiendo las demandas sociales y el desarrollo de los individuos. Es indispensable generar estrategias que permitan el desarrollo y lineamientos para gestionar los procesos que se enfrentan diariamente.

Un método, visto desde el básico concepto etimológico es un camino a través del cual se llega a un objetivo. Podríamos comprender entonces que los métodos formativos no son autónomos, si no que coexisten con la existencia de otros, para diseñar un programa de pasos a seguir para lograr objetivos educacionales.

A grandes rasgos y para comprender de una forma sencilla este concepto, podríamos explicarlo con ejemplos: cuando se presenta una problemática ante un alumno para que éste lo resuelva con esfuerzo y reflexión, respetando su libertad de pensamiento y creación, promoviendo que participe y sea protagonista de su proceso único e irrepetible de aprendizaje, tomando como directriz la correlación de los temas a estudiar con sus necesidades e intereses. Es de suma importancia ser organizados durante este proceso, para permitir que los aprendizajes nuevos recién adquiridos se integren con los previos, siendo esto posible al personalizar la enseñanza, no cayendo en el error habitual de minimizar las limitaciones y posibilidades de cada elemento. Trabajar en equipo debe ser un plan complementario a las actividades individuales, ya que permiten el desarrollo de un pensamiento crítico y analítico. 
Como bien mencionaban (Michavila y Calvo,1998), para tales innovaciones docentes se requiere formar a los futuros profesores sin dejar la adquisición de dichas capacidades a la intuición e imaginación de cada uno. No se trata de una cuestión voluntarista sino de nuevas exigencias profesionales. La metodología docente tiende a complementar la formación tradicional y propone nuevas formas de identificar las necesidades que existen en el desarrollo y capacitación de competencias, entrelazadas con los aspectos psicológicos y emocionales que conlleva, para definir procesos individuales y grupales, de gestión por competencias y orientadas siempre al aprendizaje continuo.

Podríamos delimitar estos métodos en 4 ramas principales:

1) Saber. Conocimientos técnicos que están orientados al desarrollo y conocimientos sociales orientados a las relaciones interpersonales, que los aprendices deberán de tener en cada fase del desarrollo de su proceso y metodología de aprendizaje.

2) Saber hacer. Tener habilidades que permitan poner en práctica los conocimientos que ya se tienen:

- Habilidades emocionales: para el control de sus estados anímicos

- Habilidades sociales: para establecimiento de redes

- Habilidades cognitivas: para un adecuado procesamientode la información

- Habilidades técnicas: para desempeñar las tareas y actividades

- Habilidades directivas: para el liderazgo de su propio proceso, individual y grupal.

3) Saber estar: para que exista una concordancia entre el que aprende y su entorno organizacional, para detectar cuales son los valores, actitudes y creencias del sujeto y su capacidad a la adaptación de estos cambios.

4) Querer hacer: encontrar que motiva al individuo a comportarse de una $u$ otra forma, para mostrarle la necesidad y utilidad de adoptar 
comportamientos precisos para conseguir resultados exitosos, para que pueda ser capaz de gestionar su propia motivación con el fin de desarrollar un comportamiento consciente y exitoso para alcanzar las metas que se estipulen.

5) Poder hacer. Esto se divide en 2 puntos de vista, el individual y el situacional. el primero es referente al estudio de las capacidades personales para llevar a cabo un proceso, que nos permita desplegar acciones formativas para fortalecer las capacidades carentes o nulas. El segundo es referente al entendimiento del grafo de favorabilidad del medio, analizando el entorno educativo para canalizar las ayudas e iniciativas institucionales en pro del beneficio de la misma organización.

En suma, se trata de cambiar el papel secundario tradicionalmente atribuido a los métodos de la docencia. Sustentando esta premisa Pérez Gómez (1981) afirma que el problema de los métodos es, sin duda de carácter instrumental. Pero instrumental no es sinónimo de secundario.

Lo instrumental es, en cuanto tal, ineludible. Descuidar la atención de los métodos con la intención de dedicarse a los contenidos es un falso camino; porque los métodos sin perder su función instrumental- pueden impedir, si no son adecuados, la transmisión de cualquier contenido". A ello hemos de añadir que los métodos tienen una función básica y primordial en la configuración de los contenidos, y aún más en el caso de los métodos de enseñanza.

Para tener de igual forma una estructura más delimitada, es necesario plasmar los 3 pasos o etapas de este proceso:

\section{- Preparación \\ - Desarrollo \\ - $\quad$ Evaluación}

En la preparación, es necesario que el profesor tenga en mente los objetivos generales de lo que se desee lograr, refiriendo conocimientos básicos, términos nuevos, actitudes habilidades y valores concretos. Una vez realizado esto, el docente debe 
seleccionar los contenidos de acuerdo con las capacidades del alumnado y estructurar la dinámica de aprendizaje con medios complementarios que sean oportunos.

Laing $(1968,25-27)$ señala nueve puntos fundamentales para esta preparación:

- Conocer a fondo la materia

- Tener en cuenta el tipo de auditorio

- $\quad$ Prever para cada lección un comienzo o introducción, un núcleo y un final

- $\quad$ Planificar la estructura de modo que ayude a comenzar por el principio y

- $\quad$ recorrer los puntos más interesantes.

- $\quad$ Partir de unas notas básicas. No hace falta, sin embargo, tener todo escrito

- $\quad$ No perder de vista que se trata de palabra hablada y no escrita

- $\quad$ Tener en cuenta el tiempo que dura la lección magistral

- $\quad$ Prever las posibles ayudas audiovisuales

- $\quad$ Recordar, al preparar la clase, que lo que le aburre al profesor, aburrirá al

- $\quad$ auditorio.

Además de todos estos puntos mencionados, es muy importante tener en cuenta la comunicación verbal y no verbal, ya que prestarle atención exclusivamente al contenido de la clase no tendrá el mismo efecto y resultado que si se plantea y comunica adecuadamente.

Todo intento para mejorar la efectividad del proceso, debe considerar 3 ámbitos principalmente: 
1. Relación y expresión. Hacer buen uso del lenguaje común y técnico cuando es debido, apoyarse de medios didácticos y hacer la interacción de ambos algo fluido y entendible.

2. Científico. Debe abastecer las necesidades de los variados temas, objetividad de la exposición y buena estructura.

3. Directriz del alumno y de su aprendizaje. Atender e incentivar su participación activa, con preguntas generadas por el alumno o bien, hechas hacia él. Esto refuerza la profundización y el interés para entenderlo y procesarlo.

Para que exista una correcta enseñanza es indispensable contar con comunicación, para que el alumno asimile con claridad toda la información y la convierta en solido conocimiento. Es primordial promover el conocimiento por comprensión y entendimiento, crear la necesidad de seguir aprendiendo y un ambiente de trabajo colaborativo entre los alumnos y también reforzar el trabajo individual, permitiéndole a los estudiantes asumir la responsabilidad y protagonismo de su propio aprendizaje.

\section{¿CÓMO ESTOS ELEMENTOS PUEDEN CONVERTIRSE EN LAS BASES PARA NUEVAS HERRAMIENTAS EDUCATIVAS?}

Para que exista una verdadera calidad educativa, debe existir una relación estrecha entre el liderazgo y la comunicación, que ya desde su interacción, coexisten en este ámbito. Según Cano (1998, citado por García, 2005), uno de los factores fundamentales para el logro de una educación de calidad es el liderazgo del equipo directivo de la institución. Es necesario un liderazgo visible de la dirección, un liderazgo eficaz basado en el compromiso con la calidad, cultura en la que el líder ha de hacer partícipe a todos los miembros de la comunidad educativa. Por eso, para que esa situación se cumpla debe haber motivación del alumnado, hábitos y actitudes ante el trabajo intelectual, actitudes intelectuales, nivel del profesorado, modelo de enseñanza, trabajo en equipo, clima institucional, lo cual conlleva a la satisfacción estudiantil.

Así mismo, Cano plantea que se debe cambiar para tener una preparación académicamente en forma y para ser más eficaces en el logro de los objetivos como personas, comunidades e instituciones. Además, dice: 
No es con excusas, arguyendo falta de condiciones óptimas, lo que va a mejorar la educación costarricense, sino la actitud positiva y el liderazgo efectivo de cada uno de nosotros. Los que hemos tenido la oportunidad de laborar en las aulas de este país allende nuestras fronteras en zonas urbanas y rurales, en todos los niveles del sistema educativo, sabemos que nunca vamos a tener esas condiciones óptimas, por eso debemos escudarnos en este tipo de excusas para negarnos la oportunidad de tener éxito. (p. 17)

Por otra parte, están aspectos como las relaciones humanas, la escucha, atención de quienes conforman el salón de clases y la institución en general, fuentes como docente y estudiante, que puedan convivir y salir adelante. Si en el muchacho que le disparó a una directora hubiera habido motivación, no hubiera sido capaz de realizar ese acto delictivo porque hubiese pensado en las consecuencias negativas que esa actitud le traería a él, a la familia, a la institución, a los compañeros y compañeras y a la directora. Por consiguiente, en el rol docente se debe trabajar no solo el área de los conocimientos, las habilidades, las destrezas, las actitudes, sino también aspectos como la motivación y la comunicación, pilares fundamentales para que haya buenas relaciones interpersonales no solo en un centro educativo sino también dentro de la sociedad.

Es aquí donde podríamos definir que el principal objetivo de la implementación de estos procesos en la docencia es consolidar la carrera profesional.

Las cuatro etapas del desarrollo de la carrera profesional.

Etapa 1: Depender de otras personas.

En esta etapa, el estudiante acepta sin mayores problemas ser dirigida por otros. Los que se encuentran en la misma muestran competencias en un aparte de un proyecto más amplio, pero suelen centrarse en tareas muy concretas y rutinarias. La mayor parte de las personas pasan por esta etapa un tiempo limitado. El principal enfoque psicológico de esta etapa es la dependencia, y durante la misma no ejercen ninguna muestra de liderazgo. Algunas personas no salen nunca de esta etapa, otras hacen la transición a la siguiente etapa, pero en ocasiones bien por quedarse anticuados bien por no poseer las competencias necesarias regresan a esta etapa. 


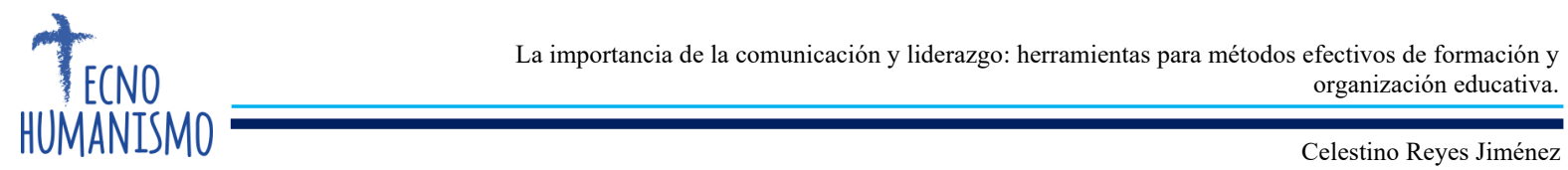

Etapa 2: Contribución independiente.

Consiste en una serie de comportamientos que llevan al estudiante a asumir responsabilidades en un proyecto de forma autónoma. Esta persona genera resultados importantes con lo que adquiere mayor conocimiento y experiencia, junto con un buen prestigio. Es muy importante afianzar en esta etapa la adquisición de competencias, el desarrollo de experiencia para tener éxito en la siguiente etapa más que intentar salir rápidamente de la misma sin alcanzar un nivel competencial adecuado.

Etapa 3: Contribuir a través de otros.

Muchas personas que ostentan el título de director/a no han llegado a esta etapa, sino que siguen en la segunda, y siguen actuando más como un componente individual que como un líder de grupo. El comportamiento específico de esta etapa requiere que el líder desarrolle a los demás, que represente a la organización ante grupos y organizaciones externas, y construya redes tanto internas como externas. Producen un impacto organizacional a través de las enseñanzas y consejos que dan a los demás, a través de asumir la responsabilidad de un proyecto, y a través de la asunción de una responsabilidad mucho mayor que la relativa a su propio rendimiento.

Etapa 4: Convertirse en líderes.

Los estudios muestran que sólo el $5 \%$ de la población trabajadora alcanza las funciones de la etapa 4. Esto significa que obviamente que el $95 \%$ de todos los que trabajan en una organización pueden tener una carrera profesional muy satisfactoria sin llegar a esta cuarta etapa.

Desde el punto de vista de la gestión del cambio organizacional, Zenger y Folkman indican las competencias que debe tener un líder para liderar el cambio organizacional:

- Tiene una capacidad para abanderar el cambio en la organización.

- Lidera proyectos o programas logrando el apoyo de los demás.

- $\quad$ Muestra una perspectiva estratégica. 
- Sabe que su trabajo tiene relación con la estrategia de negocio o finalidad de la organización.

- Traduce la visión y objetivos de la organización en metas estimulantes e importantes para los demás.

- $\quad$ Tiene una perspectiva a largo plazo; se puede confiar en su persona par que equilibre las necesidades de corto con las necesidades a largo plazo.

- $\quad$ Conecta el mundo exterior con los equipos internos.

- $\quad$ Representa a su equipo ante los grupos clave externos

- Ayuda a los demás a comprender que la satisfacción de las necesidades de los usuarios (estudiantes/padres/sociedad/ es básica para la misión y objetivos de la organización.

- $\quad$ Sin duda alguna, todas estas bases trasmutan a pasos acelerados permitiéndonos conocer nuevas técnicas y procesos para la optimización.

\section{CONCLUSIONES}

A lo largo de este artículo hemos revisado conceptos, citado autores y realizado un análisis minucioso acerca de este tema tan interesante desde lo mas general a lo particular. Comunicarnos acertada y eficazmente, crear lideres en los diferentes eslabones de las comunidades estudiantiles e implementar prácticas de provecho para éstas, nos aseguran una transformación en la forma de aprender y enseñar que desde tiempos milenarios hemos llevado a cabo como humanos necesitados de entender nuestro entorno y evolucionar.

Las organizaciones educativas tienen un sistema central de valores compartidos que construyen la estrategia, el sistema y su estructura sobre bases sólidas sustentadas en su filosofia institucional. Sin embargo, son las personas quienes la hacen posible con su liderazgo, que otorga poder y autoridad, y genera más innovación, iniciativa y compromiso. La ética no se ve como concepto sino como valor compartido cuando se 
aprende y se vive éticamente, es decir, es ser ético con principios y valores que constituyen la cultura organizacional.

En síntesis, el liderazgo educativo se construye en la relación de todos los elementos expresados hasta ahora y en la interacción del sentido pedagógico con la innovación y la creatividad de sus líderes y la cohesión entre la visión de futuro de la organización, teniendo en cuenta el desarrollo humano y la comunicación eficiente de las personas que la componen.

Se puede concluir que tiene que ver con las personas y sus comportamientos frente a sus cualidades, características y competencias de los líderes a nivel individual, lo cual se proyecta en toda la organización educativa. En consecuencia, las competencias directivas refuerzan el liderazgo educativo representado en los líderes, y que, por ende, promueven la calidad educativa y la eficiencia en sus procesos.

La sostenibilidad es fuente del desarrollo educativo, en cuanto a los factores que influyen en la formación, como es lo social, económico y ambiental, mediado por la ética, con relación a los principios y valores. El liderazgo educativo en el sentido de lo humano, trasciende a lo profesional y genera cultura de la innovación y la creatividad.

"Un buen líder lleva a las personas a donde quieren ir. Un gran líder las lleva a donde no necesariamente quieren ir, pero deben de estar." (Rosalynn Carter)

"El arte de la comunicación es el lenguaje del liderazgo." (James Humes)

\section{REFERENCIAS}

Elizondo, M. (Marzo de 2000). Asertividad y escucha activa en el ámbito académico. México, Editorial $\quad$ Trillas. $\quad$ Obtenido de http://wvw.nacion.com/viva/2003/marzo/28/soc1.html

Kaplún, M. (1 de Junio de (1997).). De medios y fines en comunicación educativa. Quito, Ecuador. Obtenido de http://hdl.handle.net/10469/12869

Farías Martínez, G. M. (2017). ¿Existe Relación entre la Gestión Administrativa y la Innovación Educativa? Revista Iberoamericana sobre Calidad, Eficacia y Cambio en Educación, 61-90. Recuperado el 20 de octubre de 2020, de https://doi.org/10.15366/reice2017.15.1.002 
Díaz Delgado, Miguel Ángel (2019). La complejidad de la investigación en liderazgo educativo, acercamientos metodológicos contemporáneos. Revista Electrónica "Actualidades Investigativas en Educación", 19(1),1-19. [fecha de Consulta 20 de octubre de 2020]. Disponible en: https://www.redalyc.org/articulo.oa?id=447/44759854021

Gorrochategui Martell, Alfredo (2012). LIDERAZGO EDUCATIVO Y SUS COMPETENCIAS. UNA PROPUESTA DE FORMACIÓN DOCENTE. Atenas, 2(18),126-147. [fecha de Consulta 20 de octubre de 2020]. Disponible en: $\underline{\text { https://www.redalyc.org/articulo.oa?id=4780/478048954009 }}$

López Leiva, Verónica (2010). LIDERAZGO Y MEJORA EDUCATIVA. Psicoperspectivas, 9(2),1-8. [fecha de Consulta 20 de octubre de 2020]. ISSN: 0717-7798. Disponible en: https://www.redalyc.org/articulo.oa?id=1710/171015625001

Sánchez, A. V. (2015). Importancia e impacto del liderazgo educativo. Padres y Maestros/Journal of Parents and Teachers, (361), 6-11.

Pareja Fernández de la Reguera, J. A. (2009). Liderazgo y conflicto en las organizaciones educativas. Educación y educadores, 12(1), 137-152.

Molina, O. A. M., Villegas, O. A. M., Villegas, R. A. M., \& Oliveros, M. N. L. (2018). Comunicación para el Liderazgo en las Instituciones Educativas en el Contexto de la Complejidad. Revista Scientific, 3(9), 190-213.

Silvera Tumbaco, C. J. (2019). Comunicación interna y liderazgo transformacional de los docentes en una institución educativa básica, Guayaquil-Ecuador, 2018.

Rivilla, A. M., \& Díaz, R. M. G. (2014). El liderazgo pedagógico: competencias necesarias para desarrollar un programa de mejora en un centro de educación secundaria. Perspectiva Educacional, Formación de Profesores, 53(1), 91-113.

Parra Rivas, R. (2011). Liderazgo transformacional del director y desempeño laboral de los docentes. Revista científica digital del centro de investigación y estudios gerenciales, 2, 54-72. 


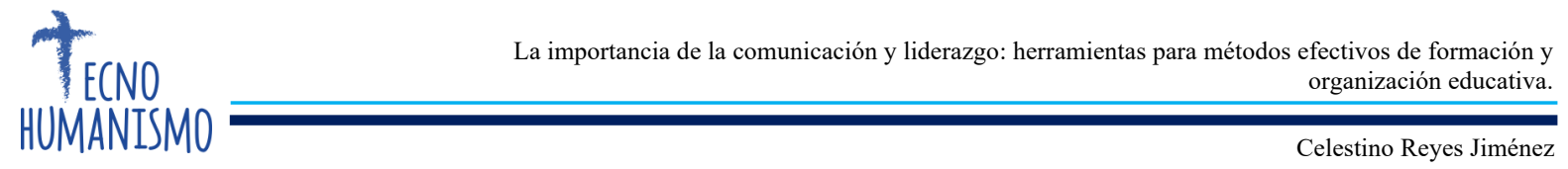

Mora, A. C. (2011). Liderazgo y educación: hacia una gestión educativa de calidad. Gestión de la educación, 144-165.

Vera-Mendoza, M. B. (2018). Las competencias laborales como eje formativo para mejorar el desempeño organizacional. Maestro y Sociedad, 42-54.

Pagani, M. (2009). El cambio organizacional y la política formativa: análisis de una experiencia local. Ciudad de la Plata.

Sánchez, J. C., Lanero, A., Yurrebaso, A., \& Tejero, B. (2007). Cultura y desfases culturales de los equipos de trabajo: implicaciones para el compromiso organizacional. Psicothema, 19(2), 218-224.

Rondón, M., \& Ammar, M. (2016). Gestión del talento humano en organizaciones educativas. Revista de investigación, 40(88), 148-165.

Lorenzo Delgado, M. (2004). La función de liderazgo de la dirección escolar: una competencia transversal.

Tapia-Gutiérrez, C. P., Becerra-Peña, S., Mansilla-Sepúlveda, J., \& Saavedra- Muñoz, J. (2011). Liderazgo de los directivos docentes en contextos vulnerables. Educación y educadores, 14(2).

Castro, E. P., Hernández, C. G., Romero, R. M., \& Bravo, G. R. (2010). Modelo estratégico de comunicación educativa para entornos mixtos de aprendizaje: estudio piloto. Pixel-Bit. Revista de medios y educación, (37), 43-55.

Morales, L. G., \& López, G. L. (2010). La comunicación educativa en el aula: una alternativa para la enseñanza de las Teorías de la Comunicación. Diálogos de la comunicación, (80), 16.

Peña, R. D. P., \& Fernández, M. D. L. A. A. (2013). La inteligencia emocional como una herramienta de la gestión educativa para el liderazgo estudiantil. Cuadernos de administración, 29(50), 132-141.

Argos, J., \& Ezquerra, P. (Eds.). (2014). Liderazgo y educación. Ed. Universidad de Cantabria. 
Perdomo, Y., \& Prieto, R. (2009). El liderazgo como herramienta de competitividad para la gerencia del servicio. CICAG: Revista del Centro de Investigación de Ciencias Administrativas y Gerenciales, 6(2), 30-48.

Vargas, G. M. G., \& Delgado, V. H. O. (2010). Liderazgo para una gestión moderna de procesos educativos. Revista Educación, 34(1), 15-29. 